TABLE 2

\begin{tabular}{|c|c|c|c|}
\hline $\begin{array}{c}\text { Controls } \\
87 \%(12)\end{array}$ & 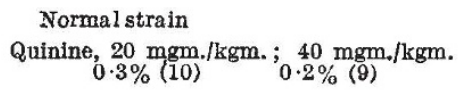 & $\begin{array}{l}\text { Controls } \\
79 \%(10)\end{array}$ & $\begin{array}{c}Q 51 \\
\text { Quinine, } 20 \mathrm{mgm} . / \mathrm{kgm} . ; \\
78 \%(10)\end{array}$ \\
\hline & & & $Q 53$ \\
\hline $77 \%(8)$ & $\begin{array}{c}30 \underset{0.1 \%}{\mathrm{mgm}} / \mathrm{kgm} . \\
0.10)\end{array}$ & $63 \%(9)$ & $20 \underset{56 \%(6)}{\mathrm{mgm} . / \mathrm{kgm} .} ; 30 \underset{18 \%(10)}{\mathrm{mgm} / \mathrm{kgm} .}$ \\
\hline
\end{tabular}

experiments have been begun to ascertain if quinine resistance might be increased.

The essential difference between my experiments and those of Williamson, Bertram and Lourie is the fact that they used very large doses (150 mgm. $/ \mathrm{kgm}$. daily in 516 out of 870 days) as compared to my doses of 20 , later $40 \mathrm{mgm}$. $/ \mathrm{kgm}$. daily, with three drugless days every week. How this difference bears on experiments with mepacrine, sulphadiazine and 3349 (I.C.I.) remains to be examined.

A further series of experiments served to examine if resistance is maintained after passage through the mosquito (Aedes cegypti) (see Table 3).

TABLE 3

\begin{tabular}{|c|c|c|}
\hline $\begin{array}{l}\text { Controls } \\
87 \%(5)\end{array}$ & $\begin{array}{l}\text { Normal strain } \\
\text { Quinine, } 20 \mathrm{mgm} . / \mathrm{kgm} . \\
0.2 \% \text { (10) }\end{array}$ & $\begin{array}{l}Q 55 \text { (through mosquito) } \\
\text { Controls Quinine, } 20 \text { mgm. } / \mathrm{kgm} \text {. } \\
43 \% \text { (9) } \\
8 \%(10)\end{array}$ \\
\hline
\end{tabular}

Repetition of these experiments had the same results. So after one passage through the mosquito, acquired resistance to quinine is partially lost, in contrast with the persistence of acquired 'Paludrine' resistance. As regards quinine, this result agrees with those of Kritschewski and Halperin ${ }^{4}$ (Plasmodium relictum), if one interprets their tables correctly.

The quinine-resistant strain appeared to be nonresistant to mepacrine, 'Paludrine' and chloroquine, because minimal active doses were as effective in the quinine-resistant strain as in a normal strain.

At present $I$ am experimenting on the reaction of the secondary cinchona alkaloids and other antimalarials. Also series of related experiments (inoculation of $E E$ forms, loss of resistance, etc.) are in progress.

A detailed account of my results will be published later. I am indebted to the Imperial Chemical (Pharmaceuticals), Ltd., for the gift of 'Paludrine', and to the Nederlandsche Kininefabriek for the specially purified cinchona alkaloids. I am also grateful to Dr. F. Hawking (National Institute of Medical Research) for introducing me to the modern technique with Plasmodium gallinaceum and for putting a strain at my disposal; also to Dr. D. G. Davey, who demonstrated his laboratory technique. The experiments were carried out with the technical assistance of Miss Ella Pauw.

Malariological Laboratory

A. TH. KNOPPERS

of the Combination Amsterdamsche-,

Nederlandsche- and Bandoengsche

Kininefabriek,

Amsterdam.

July 7.

${ }^{1}$ Bishop, A., and Birkett, B., Nature, 159, 884 (1947).

Williamson, J., Bertram, D. S., and Lourie, E. M., Nature, 159, 885 (1947).

${ }^{3}$ Marshall, P. B., J. Pharm., 85, 299 (1945)

Kritschewski, T. L., and Halperin, E. P., Z. Immunforsch., 79, 149 (1933).

\section{Freezing as an Aid in the Drying and Purification of Humus and Allied Materials}

IT is well known in colloid chemistry that the freezing of gels may cause coagulation, which is in some cases irreversible. We have found little evidence, however, that this phenomenon has been used to any great extent as a laboratory technique to simplify the bulk preparation of materials of a colloidal character.

In our work on soil organic matter, it is necessary to filter, reprecipitate and refilter frequently acidprecipitated flocculæ of humic acids (that is, materials allied to 'alkali-lignin' which constitute the bulk of soil organic matter). These materials, because of their large bulk, colloidal character and waterretaining capacity (greater than ten times their dry weight), are extremely difficult to filter and dry.

It has been found that, if the precipitates are frozen solid to a temperature of at least $-3^{\circ} \mathrm{C}$. and then allowed to thaw, the colloidal properties are destroyed and the solid and aqueous phases separate. Moreover, the solid is in a condensed form, as irregular microscopic flakes, which are very readily filtered by standard methods.

The moisture content of a humus preparation has been reduced to one thirtieth of the original by a single freezing and thawing.

The colloidal character of the materials having been destroyed, they not only lose their waterholding capacity but also their general adsorptive power. Therefore, by washing with water, soluble contaminants are readily removed and a considerable degree of purification attained.

The presence of electrolytes is necessary for the freezing effect to take place, since in their absence the material reverts to its colloidal form on thawing.

The condensed humus can be regenerated in normal form by solution in alkali and precipitation with acid. The raw materials (soil, peat, or decomposed vegetable matter) are extracted with dilute ( 2 per cent) caustic soda and the alkaline extract acidified with sulphuric acid to a $p H$ of approximately 3. The precipitated humus is allowed to settle, and after the supernatant liquor has been siphoned off, is frozen to $-3^{\circ} \mathrm{C}$. It is then allowed to thaw, filtered, washed, and because of its small bulk and non-adsorptive powers is readily completely dried by standard methods.

The method is applicable to materials of similar properties such as 'alkali-lignin' precipitated from the waste liquors in the soda process, and may indeed have wide application in simplifying the preparation of plant structural substances in a readily handled form.

W. G. C. Forsyth

G. K. Fraser

Macaulay Institute for Soil Research, Craigiebuckler, Aberdeen. July 1. 